Editorial

\title{
Special Issue: Accident Analysis and Prevention: Experimental and Numerical Approaches
}

\author{
Ricardo J. Alves de Sousa ${ }^{1}\left(\mathbb{D}\right.$ and Mariusz Ptak ${ }^{2, * \mathbb{C}}$ \\ 1 TEMA-Centre for Mechanical Technology and Automation, Department of Mechanical Engineering, \\ University of Aveiro, Campus de Santiago, 3810-193 Aveiro, Portugal; rsousa@ua.pt \\ 2 Faculty of Mechanical Engineering, Wroclaw University of Science and Technology, Lukasiewicza 7/9, \\ 50-371 Wrocław, Poland \\ * Correspondence: mariusz.ptak@pwr.edu.pl; Tel.: +48-713202946
}

Received: 3 January 2020; Accepted: 6 January 2020; Published: 10 January 2020

\section{Introduction}

Accidents are a daily occurrence in our lives, in many different activities and scenarios, from sports to traffic, from home to work environments, from non-intentional to criminal offences. The usual outcome is some kind of injury, which can range from minor, soft injuries to severe, lethal injuries.

Numerical and experimental methods have been continuously improved in order to provide better analysis of accident scenarios, evaluate their outcomes, and provide effective frameworks for their prevention.

This publication encloses a set of contributions on topics that include studies of human and environmental aspects prior to accidents; the type and severity of accidents; the design and implementation of passive and active protective devices; the biomechanics of impact and resulting injuries; and statistics and decision-making tools. The book highlights the importance of numerical and experimental methods, which can serve as a powerful tool to study and enhance safety.

\section{Special Issue Papers}

The topics just referred to were addressed in several chapter of the book. Regarding road and traffic aspects, Yim et al. discuss the "Development of Navigator Behavior Models for Evaluation of Collision Avoidance Behavior in the Collision-Prone Navigation Environment" [1] whereas Ptak addressed a "Method to Assess and Enhance Vulnerable Road User Safety During Impact Loading" [2] using numerical modeling and proposing some countermeasures for Vulnerable Road Users.

The role of numerical modeling was also addressed by Tierney and Simms, regarding the "Predictive Capacity of the MADYMO Multibody Human Body Model Applied to Head Kinematics During Rugby Union Tackles" [3].

Occupational and work-related accidents were addressed by Shafique and Rafiq, "An Overview of Construction Occupational Accidents in the Hong Kong: A Recent Trend and Future Perspectives" [4], whereas Kakhki and co-workers discussed the "Use of Logistic Regression to Identify Factors Influencing the Post-Incident State of Occupational Injuries in Agribusiness Operations" [5]. Also on the civil construction domain, Derlukiewicz discussed the "Application of a Design and Construction Method Based on a Study of User Needs In The Prevention of Accidents Involving Operators of Demolition Robots" [6].

Head protection devices to save lives deserved particular attention as demonstrated in Jamroziak et al., "The Ballistic Head Protection in the Light of Injury Criteria on the Example of the Wz.93 Model Combat Helmet" [7] and also by Fernandes et al. "Helmet Design Based on the Optimization of Biocomposite Energy Absorbing Liners Under Multi-Impact Loading" [8]. Sławiński 
et al. outlined the problem regarding the development of soldiers' injuries, caused as a result of strong effects of pulse forces, inside armored vehicles [9].

In the world of sports, this book presents the contribution "Mortality of NBA players: Risk Factors and Comparison with the General US Population", by Martinez et al. [10].

Finally, because traffic accidents may also happen in other environments besides streets and highways, Youn and co-workers contributed with the work "Analysis of Lookout Activity in a Simulated Environment to Investigate Maritime Accidents Caused by Human Error" [11].

It becomes evident that the field of traffic safety is huge, and with plenty of room for continuous development. The present book sheds some light on some of its subtopics of relevance.

Acknowledgments: The guest editors would like to thank all the authors for submitting their excellent work to this special issue. Furthermore, we would like to thank all the reviewers for their outstanding job in evaluating the manuscripts and providing helpful comments. The guest editors also would like to thank the MDPI team involved in the preparation, editing, and managing of this special issue. Finally, we would like to express our sincere gratitude to Lucia Li, the contact editor of this special issue, for her kind, efficient, professional guidance and support through the whole process. We would not have been able to reach the above collection of high quality papers without this joint effort. Ricardo Alves de Sousa is currently Assistant Professor with habilitation at the Department of Mechanical Engineering of the University of Aveiro (Portugal) and member of the Center of Mechanical Technology (TEMA) research unit. In 2006, he obtained a PhD degree in Mechanical Engineering from the University of Aveiro, Portugal. He has more than 100 scientific contributions either in papers, book chapters and books, and he is author of three patents. In 2011, he received the international scientific ESAFORM (European Association of Material Forming) career prize. In 2013 he received the Innovation Prize from APCOR (Portuguese Association for Cork), and in March of 2015 researcher of month at the University of Aveiro. Mariusz Ptak is a Mechanical Engineer at Wroclaw University of Science and Technology (Poland) with many years of experience in Computer-aided Design/Engineering (CAD/CAE), finite element/multibody simulations of real world problems in nonlinear dynamics with emphases on pedestrian and cyclist safety, vehicle crashworthiness, injury biomechanics. A laureate of "Top 500 Innovators" program at Stanford University, where he took his first steps in Design Thinking. Also, since 2013 he has been an IPMA Certified Project Management Associate and a certified soft skills trainer. Currently, Mariusz is a leader of the international grant aHEAD (www.aheadproject.org) focused on head injuries.

Conflicts of Interest: The authors declare no conflict of interest.

\section{References}

1. Yim, J.-B.; Park, D.-J.; Youn, I.-H. Development of navigator behavior models for the evaluation of collision avoidance behavior in the collision-prone navigation environment. Appl. Sci. 2019, 9, 3114. [CrossRef]

2. Ptak, M. Method to assess and enhance vulnerable road user safety during impact loading. Appl. Sci. 2019, 9, 1000. [CrossRef]

3. Tierney, G.J.; Simms, C. Predictive capacity of the MADYMO multibody human body model applied to head kinematics during rugby union tackles. Appl. Sci. 2019, 9, 726. [CrossRef]

4. Shafique, M.; Rafiq, M. An overview of construction occupational accidents in Hong Kong: A Recent Trend And Future Perspectives. Appl. Sci. 2019, 9, 2069. [CrossRef]

5. Davoudi Kakhki, F.; Freeman, S.A.; Mosher, G.A. Use of logistic regression to identify factors influencing the post-incident state of occupational injuries in agribusiness operations. Appl. Sci. 2019, 9, 3449. [CrossRef]

6. Derlukiewicz, D. Application of a design and construction method based on a study of user needs in the prevention of accidents involving operators of demolition robots. Appl. Sci. 2019, 9, 1500. [CrossRef]

7. Jamroziak, K.; Bajkowski, M.; Bocian, M.; Polak, S.; Magier, M.; Kosobudzki, M.; Stepien, R. Ballistic head protection in the light of injury criteria in the case of the Wz.93 combat helmet. Appl. Sci. 2019, 9, 2702. [CrossRef]

8. Fernandes, F.; Alves de Sousa, R.; Ptak, M.; Migueis, G. Helmet design based on the optimization of biocomposite energy-absorbing liners under multi-impact loading. Appl. Sci. 2019, 9, 735. [CrossRef]

9. Sławiński, G.; Malesa, P.; Świerczewski, M. Analysis regarding the risk of injuries of soldiers inside a vehicle during accidents caused by improvised explosive devices. Appl. Sci. 2019, 9, 4077. [CrossRef] 
10. Martínez, J.; Langohr, K.; Felipo, J.; Casals, M. Mortality of NBA players: Risk factors and comparison with the general US population. Appl. Sci. 2019, 9, 500. [CrossRef]

11. Youn, I.-H.; Park, D.-J.; Yim, J.-B. Analysis of lookout activity in a simulated environment to investigate maritime accidents caused by human error. Appl. Sci. 2018, 9, 4. [CrossRef]

(C) 2020 by the authors. Licensee MDPI, Basel, Switzerland. This article is an open access article distributed under the terms and conditions of the Creative Commons Attribution (CC BY) license (http://creativecommons.org/licenses/by/4.0/). 